\title{
Oral health attitudes and caries-preventive behaviour of Czech parents of preschool children*
}

\author{
Erika Lenčová, Jana Dušková
}

Institute of Clinical and Experimental Dentistry - 1st Faculty of Medicine of the Charles University and General Faculty Hospital in Prague, Czech Republic

\author{
Corresponding author: \\ Erika Lenčová \\ Institute of Clinical and Experimental \\ Dentistry \\ 1st Faculty of Medicine of \\ the Charles University in Prague \\ and General Faculty Hospital \\ Karlovo nám. 32, 12120 Prague \\ Czech Republic \\ lencova@vus.cz \\ Tel.: + 420224966824 \\ Fax.: + 420224966840
}

Received: 3 May 2013 Accepted: 3 June 2013

Copyright (C) 2013 by Academy of Sciences and Arts of Bosnia and Herzegovina. E-mail for permission to publish: amabih@anubih.ba

\begin{abstract}
Objective. To characterize the oral health-related attitudes and behaviour of Czech parents of preschool children. Materials and methods. A representative sample of 796 parents was recruited for the crosssectional questionnaire survey. Study data were collected using a validated questionnaire with 44 attitudinal items related to different aspects of caries prevention. The data were analyzed by explorative factor analysis, extracted factors were subjected to reliability analysis and Kruskal-Wallis ANOVA was used to test differences in the factor scores in respondents with different levels of education and selfperceived SES. Results. The factor analysis extracted 3 factors, labelled "Toothbrushing - perceived significance and parental efficacy"; "External caries control" and "Internal caries control". They explained $28.9 \%$ of the data variability. The comparison of the factor scores in groups with different SES and education of mothers showed highly significant differences. For all three factors, median values of the aggregated Likert scale increased with increasing SES and education of the mother. Conclusion. The parents report that they are aware of their responsibility for the prevention of tooth decay in their children. In caries prevention they concentrate on toothbrushing. Dietary measures do not seem to be of similar importance to them. The increasing self-perceived SES of the family and the education level of the mother have a significantly positive effect on the caries-preventive attitudes of the parents. Based on the study results, the message to the publichealth sector in the Czech Republic should include the need to highlight the importance of a non-cariogenic diet and the role of fluorides in caries prevention.
\end{abstract}

Key words: Childhood caries, Oral health-related attitudes, Questionnaire survey, Socio-economic status.

\section{Introduction}

The main aetiological factors of dental caries include cariogenic bacteria, frequent intake of fermentable carbohydrates, disorders of salivary production and the composition and poor mineralization of hard dental tissues (1). The above-mentioned major risk factors are modified by socioeconomic, psychological and behavioural risk factors, which act as indirect causal agents (2) and

${ }^{*}$ The article is dedicated to professor Zdenek Broukal on the occasion of his 70th birthday, with gratitude and appreciation, professionally and personally. 
help explain the distribution of dental caries within the population. The Czech Republic is a country with relatively high caries prevalence in preschool children. In 2010, the proportion of 5yr-old children with intact teeth was 45 percent (3).

Thus, the aim of this cross-sectional questionnaire survey was to characterize oral health-related attitudes and the caries-preventive behaviour of Czech parents of preschool children in a representative national cohort of parents of preschool children. A similar study performed in the Czech Rep. in 2008 by Lencova et al. investigated the relationship between the parental locus of control and caries experience in preschool children, and concluded that higher internal parental locus of control is associated with better control of caries experience in their preschool children (4). The present study focused on a broader description of parental attitudes to dental caries prevention in association with their self-perceived socioeconomic status and the education level of the parents.

\section{Materials and methods}

The study was performed in 31 sites from different regions of the country. The study sites were selected, for the purposes of representative nationwide oral health surveys, by the Czech Institute of Health Information and Statistics, in compliance with the World Heath Organization recommendations (5). At each site, 1-2 nurseries were randomly selected from the national registry of preschool establishments. Subsequently, the principals of the selected nurseries were invited to join the survey. Two of the nurseries refused cooperation; therefore, alternative nurseries were selected. After obtaining the consent of the head teachers, in each nursery, the parents of 30 children aged 3-5 years were invited to participate in the question- naire survey. At the nurseries with a lower number of eligible children, parents of all the children were invited. The study was approved by the competent Ethics Committee of the General University Hospital in Prague.

The standardized and validated questionnaire used in this study was employed in an international study on childhood caries and was based on psychological theoretical models (Theory of planned behaviour, Aizen 2002, Health belief model, Rosenstock 1952 and Locus of control, Walston 1976) presenting personal attitudes and beliefs as behavioural predictors (2). The parental questionnaire contained 44 attitudinal items associated with parental oral health beliefs related to dental decay, and information on the parents' education and self-perceived socio-economical status. Each item was measured on a five-point Likert scale, ranging from strongly disagree [1] to strongly agree [5]. The coding for the negatively formulated items was reversed so that for all items higher scores reflected more positive/ correct attitudes. Missing data was imputed, allowing for up to 3 missing values. Parental education was recorded in three categories: "primary school or no formal education", "secondary school" and "college/ university". Self-perceived socio-economical status (SES) was recorded on a scale/ ladder ranging from 1-10 as "low SES" (1-3), "middle SES" (4-7) or "high SES" (8-10).

The anonymous questionnaire forms were delivered to the nurseries and, after being distributed to the parents by the school principals and filled-out, they were returned to the investigators by regular post. The data were then transfered from paper to electronic form. Out of 1248 families with preschool children invited to participate in the study, i.e. to complete the parental questionnaires, 796 questionnaires were completed (response rate: 63.8\%). 


\section{Statistical analysis}

The data were analyzed by factor analysis, which made it possible to find latent associations among a large number of variables with a similar variability, and group them into a smaller set of newly formed factors. The method of factor extraction was Principal Components Analysis (PCA) with rotation (Varimax). Factor loadings (FL), i.e. correlation coefficients between individual questionnaire variables and the factors, were calculated. Only variables with FL higher than 0.4 were included in the factors. Attitudinal items in each factor were subjected to reliability analysis to test the internal consistency of the data. From the attitudinal items of individual factors, aggregated Likert-scale scores were calculated for each individual respondent, and median values were determined in groups of respondents differing according to the level of education and selfperceived SES. Factor scores of all extracted factors were tested using Kruskal-Wallis one-way analysis of variance in groups of respondents differing according to the level of education and self-perceived SES. A probability level of 95 percent was used. The sta- tistical analyses were performed using STATISTICA 10 (StatSoft Inc.).

\section{Results}

The factor analysis extracted 3 factors, which explained $28.9 \%$ of the questionnaire data variability. The extracted factors including factor loadings of the variables, modus values and interquartile ranges are presented in Tables 1-3. Reliability analysis of each factor revealed the high internal consistency of the data - Cronbach's alpha values above 0.70 .

The factor 1 was labelled Toothbrushing - perceived significance and parental efficacy (Table 1). As is obvious from Table 1, it was related to the parents' willingness or determination to encourage and supervise their children during toothbrushing, or the positive attitudes of the "people around" towards toothbrushing. This factor explained $18 \%$ of the data variance with Cronbach's alpha value 0.82 .

Factor 2 was labelled External caries control (Table 2). This factor explained $6.3 \%$ of data variance with Cronbach's alpha value 0.75 . It included mostly health-external attitudes to caries control, related to the

Table 1 Factor 1: Toothbrushing - perceived significance and parental efficacy

\begin{tabular}{|c|c|c|c|}
\hline Items of questionnaire & Factor loading & Modus & $\begin{array}{l}\text { Interquartile range } \\
\text { (Q75-Q25) }\end{array}$ \\
\hline We feel it is important that we check our child's teeth for decay. & 0.42 & 4 & 1 \\
\hline As a family we intend brushing our child's teeth for him/her daily. & 0.64 & 4 & 1 \\
\hline $\begin{array}{l}\text { The people in my family would feel it was important to help brush our } \\
\text { child's teeth daily. }\end{array}$ & 0.64 & 4 & 1 \\
\hline $\begin{array}{l}\text { The people we know well would feel it was important to brush our } \\
\text { child's teeth daily. }\end{array}$ & 0.53 & 4 & 0 \\
\hline We feel able to brush our child's teeth for him/her. & 0.65 & 4 & 0 \\
\hline I don't know how to brush my child's teeth properly.* & 0.50 & 4 & 0 \\
\hline We feel it is important to check if our child has brushed his/her teeth & 0.62 & 4 & 1 \\
\hline We don't have time to help brush our child's teeth daily.* & 0.58 & 4 & 1 \\
\hline We cannot make our child brush his/her teeth daily.* & 0.56 & 4 & 1 \\
\hline $\begin{array}{l}\text { My child's teeth are brushed as part of my child's daily washing routine } \\
\text { (washing hands and face). }\end{array}$ & 0.59 & 4 & 1 \\
\hline
\end{tabular}

* Items were reversed before the analysis. 
parent's belief that the occurence of dental caries in their children depends on chance, luck, or the dentist.

Factor 3 was labelled "Internal caries control" (Table 3). This factor explained $4.6 \%$ of data variance with Cronbach's alpha value 0.78 . It included items related to parental awareness that it is their responsibility to control caries risk in their child, the perceived seriousness of caries occurrence in their child, and the perceived significance of cariogenic nutrition control, use of fluoride toothpastes and toothbrushing routine in the prevention of dental caries.

Table 2 Factor 2: External caries control

\begin{tabular}{|c|c|c|c|}
\hline Items of questionnaire* & Factor loading & Modus & $\begin{array}{l}\text { Interquartile range } \\
\left(\mathrm{Q}_{75}-\mathrm{Q}_{25}\right)\end{array}$ \\
\hline $\begin{array}{l}\text { It is the responsibility of the dentist to prevent our child getting tooth } \\
\text { decay. }\end{array}$ & 0.49 & 4 & 1 \\
\hline No matter what we do, our child is likely to get tooth decay. & 0.56 & 4 & 1 \\
\hline It just looks bad if our child has tooth decay. & 0.50 & 4 & 1 \\
\hline If our child gets tooth decay, it is by chance. & 0.40 & 4 & 0 \\
\hline $\begin{array}{l}\text { It would not make any difference to our child getting tooth decay, if we } \\
\text { helped him/her brush every day. }\end{array}$ & 0.52 & 4 & 1 \\
\hline It is worthwhile to give our child sweets/biscuits to behave well. & 0.43 & 4 & 0 \\
\hline In our family, it would be unfair not to give sweets to our child every day. & 0.60 & 4 & 0 \\
\hline $\begin{array}{l}\text { It is not worth it to battle with our child to brush his/her teeth twice a } \\
\text { day. }\end{array}$ & 0.42 & 4 & 1 \\
\hline It is just bad luck if our child gets tooth decay. & 0.52 & 4 & 1 \\
\hline The dentist is the best person to prevent tooth decay in our child. & 0.54 & 4 & 1 \\
\hline
\end{tabular}

*Items were reversed before the analysis.

Table 3 Factor 3: Internal caries control

\begin{tabular}{|c|c|c|c|}
\hline Items of questionnaire & Factor loading & Modus & $\begin{array}{l}\text { Interquartile } \\
\text { range }\left(Q_{75}-Q_{25}\right)\end{array}$ \\
\hline $\begin{array}{l}\text { As a family, we are confident that we can reduce the chances of our child } \\
\text { getting tooth decay }\end{array}$ & 0.47 & 4 & 0 \\
\hline $\begin{array}{l}\text { Tooth decay would have major consequences on our child's general } \\
\text { health }\end{array}$ & 0.48 & 4 & 1 \\
\hline Tooth decay is a serious problem in baby teeth & 0.51 & 4 & 0 \\
\hline $\begin{array}{l}\text { As parents, it is our responsibility to prevent our child getting tooth } \\
\text { decay }\end{array}$ & 0.49 & 4 & 1 \\
\hline $\begin{array}{l}\text { We can prevent tooth decay in our child by reducing sugary foods and } \\
\text { drinks between meals }\end{array}$ & 0.41 & 4 & 1 \\
\hline $\begin{array}{l}\text { If we brush our child's teeth daily, we can prevent our child getting tooth } \\
\text { decay in the future }\end{array}$ & 0.52 & 4 & 0 \\
\hline If our child uses a fluoride toothpaste, it will prevent tooth decay & 0.46 & 4 & 1 \\
\hline $\begin{array}{l}\text { We can prevent tooth decay in our child by helping him/her with } \\
\text { brushing daily }\end{array}$ & 0.54 & 4 & 0 \\
\hline $\begin{array}{l}\text { It would not make any difference to our child getting tooth decay, if we } \\
\text { helped him/her brush every day* }\end{array}$ & 0.42 & 4 & 1 \\
\hline $\begin{array}{l}\text { Our child eating sugary foods and drinks in between meals would cause } \\
\text { tooth decay }\end{array}$ & 0.48 & 4 & 1 \\
\hline
\end{tabular}

*Item was reversed before the analysis. 
From the 10 attitudinal items (each scored from 1 to 5 on a Likert scale by the respondents) in each of the 3 factors, aggregated Likert-scale scores were calculated for each individual respondent, ranging from 10 to 50 . These scores reflected the strength of parental attitudes within each factor from negative / incorrect (lower scores) to positive / correct (higher scores). Additionally, median values of aggregated Likert-scale scores were determined in groups of respondents with different self-perceived SES and education levels. In the above groups of respondents, the factor scores of all three factors were tested using Kruskal-Wallis one-way analysis of variance. The results are presented in Tables 4-6.

The comparison of the factor scores in groups with different self-perceived SES and the education level of the mothers showed highly significant differences $(\mathrm{p} \leq 0.005)$. For all three factors, median values of the aggregated Likert scale increased with increasing SES and education of the mother. The fathers' education had no significant effect on toothbrushing behaviour $(\mathrm{p}=0.11)$, but significantly influenced external caries control (factor $2, \mathrm{p}=0.00$ ) and internal caries control (factor $3, \mathrm{p}=0.01$ ).

Table 4 Factor scores in parents with different self-perceived socio-economical status

\begin{tabular}{|c|c|c|c|c|c|c|}
\hline \multirow[b]{2}{*}{ Variables } & \multicolumn{3}{|l|}{ SES $^{1}$} & \multicolumn{3}{|c|}{ Statistics } \\
\hline & $\begin{array}{l}\text { Low } \\
(n=61)\end{array}$ & $\begin{array}{l}\text { Middle } \\
(\mathrm{n}=596)\end{array}$ & $\begin{array}{l}\text { High } \\
(n=31)\end{array}$ & $\begin{array}{l}\mathrm{K}-\mathrm{W} \chi^{2} \\
\text { value }\end{array}$ & D. f. & $\mathrm{p}$ \\
\hline Factor 1 (Factor scores) ${ }^{2}$ & \multicolumn{3}{|c|}{ Toothbrushing - perceived significance and parental efficacy } & \multirow{2}{*}{8.15} & \multirow{2}{*}{2} & \multirow{2}{*}{0.00} \\
\hline Aggregated Likert scale (median) & 40 & 41 & 43 & & & \\
\hline Factor 2 (Factor scores) ${ }^{2}$ & \multicolumn{3}{|c|}{ External caries control } & \multirow{2}{*}{14.30} & \multirow{2}{*}{2} & \multirow{2}{*}{0.00} \\
\hline Aggregated Likert scale (Median) & 35 & 38 & 39 & & & \\
\hline Factor 3 (Factor scores) ${ }^{2}$ & \multicolumn{3}{|c|}{ Internal caries control } & \multirow{2}{*}{10.06} & \multirow{2}{*}{2} & \multirow{2}{*}{0.00} \\
\hline Aggregated Likert scale (Median) & 30 & 31 & 32 & & & \\
\hline
\end{tabular}

'Grouping variable; ${ }^{2}$ Dependent variable.

Table 5 Factor scores in groups with different maternal education level

\begin{tabular}{|c|c|c|c|c|c|c|}
\hline \multirow[b]{2}{*}{ Variables } & \multicolumn{3}{|l|}{ Maternal education level ${ }^{1}$} & \multicolumn{3}{|c|}{ Statistics } \\
\hline & $\begin{array}{l}\text { Prim. school/ no formal } \\
\text { education }(n=36)\end{array}$ & $\begin{array}{l}\text { Secondary school } \\
(n=473)\end{array}$ & $\begin{array}{l}\text { College/ } \\
\text { university } \\
\text { ( } n=254)\end{array}$ & $\begin{array}{l}\mathrm{K}-\mathrm{W} \chi^{2} \\
\text { value }\end{array}$ & D.f. & $\mathrm{p}$ \\
\hline Factor 1 (Factor scores) $)^{2}$ & \multicolumn{3}{|c|}{ Toothbrushing - perceived significance and parental efficacy } & \multirow{2}{*}{22.41} & \multirow{2}{*}{2} & \multirow{2}{*}{0.00} \\
\hline Aggregated Likert scale (median) & 40 & 40 & 42 & & & \\
\hline Factor 2 (Factor scores) ${ }^{2}$ & \multicolumn{3}{|l|}{ External caries control } & \multirow{2}{*}{32.20} & \multirow{2}{*}{2} & \multirow{2}{*}{0.00} \\
\hline Aggregated Likert scale (median) & 36 & 38 & 40 & & & \\
\hline Factor 3 (Factor scores) $^{2}$ & \multicolumn{3}{|l|}{ Internal caries control } & \multirow{2}{*}{31.16} & \multirow{2}{*}{2} & \multirow{2}{*}{0.00} \\
\hline Aggregated Likert scale (median) & 31 & 31 & 32 & & & \\
\hline
\end{tabular}

${ }^{1}$ Grouping variable; ${ }^{2}$ Dependent variable. 
Table 6 Factor scores in groups with different father's education level

\begin{tabular}{|c|c|c|c|c|c|c|}
\hline \multirow[b]{2}{*}{ Variables } & \multicolumn{3}{|l|}{ Father's education level ${ }^{1}$} & \multicolumn{3}{|c|}{ Statistics } \\
\hline & $\begin{array}{l}\text { Prim. school/ no formal } \\
\text { education } \\
(n=49)\end{array}$ & $\begin{array}{l}\text { Secondary } \\
\text { school } \\
(n=440)\end{array}$ & $\begin{array}{l}\text { College/ } \\
\text { university } \\
(n=249)\end{array}$ & $\begin{array}{l}\mathrm{K}-\mathrm{W} \chi 2 \\
\text { value }\end{array}$ & D. f. & $\mathrm{p}$ \\
\hline Factor 1 (Factor scores) ${ }^{2}$ & \multicolumn{3}{|c|}{ Toothbrushing - perceived significance and parental efficacy } & \multirow{2}{*}{3.65} & \multirow{2}{*}{2} & \multirow{2}{*}{0.11} \\
\hline Aggregated Likert scale (median) & 41 & 40 & 41 & & & \\
\hline Factor 2 (Factor scores) ${ }^{2}$ & \multicolumn{3}{|l|}{ External caries control } & \multirow{2}{*}{12.18} & \multirow{2}{*}{2} & \multirow{2}{*}{0.00} \\
\hline Aggregated Likert scale (median) & 36 & 38 & 39 & & & \\
\hline Factor 3 (Factor scores) ${ }^{2}$ & \multicolumn{3}{|l|}{ Internal caries control } & \multirow{2}{*}{9.03} & \multirow{2}{*}{2} & \multirow{2}{*}{0.01} \\
\hline Aggregated Likert scale (median) & 31 & 31 & 32 & & & \\
\hline
\end{tabular}

'Grouping variable; ${ }^{2}$ Dependent variable.

\section{Discussion}

Despite the fact that the three extracted factors explained only one third of the data variability, they had high internal consistency, showing high reliability of the scales. The factors reflected the perceived relevance of caries-preventive measures used in preschool children by Czech parents. High priority was given to toothbrushing. Its perceived significance and parental efficacy accounted for the first factor, which itself explained $18 \%$ of the data variance. The second factor reflected a perceived external locus of caries control and explained 6 percent of the data variance. The last factor was labelled "Internal caries control" and explained nearly $5 \%$ of the data variance. It included miscellaneous items related to caries prevention, including the perceived seriousness of the disease, nutritional factors and the preventive action of fluoride.

The extracted factors involved 30 out of 44 attitudinal items of the original questionnaire. This outcome is related to the exploratory factor analysis, which is a method facilitating interpretation of multiple data. Despite the fact that the original questionnaire contained attitudinal items related to nutrition or the use of fluoride toothpastes, only two nutritional items were included in Factor 2, and two nutritional items and one item related to fluoride toothpastes were in- cluded in Factor 3. This could reflect parental beliefs that prevention of the tooth decay is mainly about toothbrushing and to a lesser extent about cariogenic nutrition control or the use of fluoride.

As is obvious from Tables 1-3, parental attitudes to caries prevention were generally correct, i.e. positively oriented. Nevertheless, comparison of their attitudes according to self-perceived SES and the education level of the parents showed some significant differences. For all three factors, the median values of the aggregated Likert scale increased with increasing SES and the differences in the factor scores among the groups were statistically highly significant. The situation was similar, i.e. the differences in attitudes to caries prevention were highly significant among the groups with different levels of maternal education. The father's education had no significant effect on toothbrushing behaviour, but significantly influenced external caries control (factor 2) and internal caries control (factor 3 ). This could have been influenced by the fact that most of the questionnaires (92\%) were completed by the mothers.

\section{Assumed shortcomings of the study}

Based on the official data of the Czech statistical office, in 2011 there were 350,029 children aged 3-5 years in the Czech Repub- 
lic (6). Given the 5 percent margin of error and 95 percent desired confidence level, a minimum of 384 subjects was needed. Even though the number of subjects and stratification of the study sites in this survey was determined in accordance with the Czech Institute of Health Information and Statistics, it was not possible to recruit a completely random sample, as the participation of the subjects in the study was voluntary, based on informed consent. Based on experience from previous studies, the parents with the most negative attitudes towards the prevention of dental caries, whose children have the highest levels of caries, tend to refuse to participate.

In general, questionnaire data are selfreported, which means that respondents could have the tendency to report what they assume is expected rather than what they really believe. In addition, questionnaire items could reflect the knowledge of the respondents rather than their real behaviour. However, the acceptable response rate and stratified national sample size used in this survey increase the validity of the findings. Moreover, the results of the survey confirm the literature findings that caries-preventive behaviour in families with children is positively related to the higher SES of the family and the education level of the parents, especially the education of the mother.

\section{Conclusion}

The positive finding of this study is that Czech parents in general report that they are aware of their own responsibility for the prevention of tooth decay in their children. However, this internal control becomes more pronounced with the rising self-perceived SES of the family. A less favourable finding is that in the prevention of dental caries parents concentrate on toothbrushing, and dietary measures and fluoride do not seem to be so important to them. In- creasing self-perceived SES of the family and the education level of the mother have a significantly positive effect on caries-preventive attitudes. Based on the findings of this study, the message to the public-health sector in the Czech Republic should include the need to highlight the importance of noncariogenic diet and the role of fluorides in caries-preventive education. School-based preventive programs would probably be the most appropriate way adequately to target risk groups with low SES and low education of the parents.

Acknowledgement: Program PRVOUK-P28/LF1/6.

Authors' contributions: Conception and design: EL, JD; Acquisition and analysis of data: EL; Interpretation of data: EL, JD; Drafting the article: EL, JD; Revising it critically for important intellectual content: EL, JD.

Conflict of interest: The authors declare that they have no conflict of interest.

\section{References}

1. Featherstone JD, Adair SM, Anderson $\mathrm{MH}$, Berkowitz RJ, Bird WF, Crall JJ, et al. Caries management by risk assessment: consensus statement. J Calif Dent Assoc. 2003;31(3):257-69

2. Pine CM, Adair PM, Petersen PE, Douglass C, Burnside G, Nicoll AD, et al. Developing explanatory models of health inequalities in childhood dental caries. Community Dent Health. 2004;21:86-95.

3. Lenčová E, Pikhart H, Broukal Z. Early childhood caries trends and surveillance shortcomings in the Czech Republic. BMC Public Health. 2012;12:547.

4. Lenčová E, Pikhart H, Broukal Z, Tsakos G. Relationship between parental locus of control and caries experience in preschool children - crosssectional survey. BMC Public Health. 2008;8:208.

5. World Helath Organization. Oral health surveys: Basic methods. 4th ed. Geneva: World Health Organization; 1997.

6. Czech statistical office. Population structure according to age in 2001 [cited 2013 May 22]. Available from: http:// http://www.czso.cz/cz/pram_ dila/401912o.pdf. 